\title{
Regulatory and policy incentives - how to establish governance for decentralised energy systems?
}

\author{
Antony Froggatt and Catherine Mitchell
}

\subsection{The role of regulation and governance}

\subsubsection{Regulation as accelerator or decelerator of the energy transformation}

There are multiple ways to meet the $2^{\circ} \mathrm{C}$ reduction target of the Paris Agreement and to reach a 'deep decarbonisation' of our economies, including a reduction of primary energy consumption, the use of low-emission generation technologies such as nuclear power, or the use of carbon capture and storage. However, the most likely and cost-effective path of decarbonisation is that of renewables supplying the majority of electricity, if not the entirety (GEA 2012; IPCC 2015; Greenpeace 2015) alongside significant energy efficiency measures, whether minimising energy use in buildings through retrofit programmes or via the markets, ensuring the demand side is as valuable as the supply side. That will require not only new policies and significant changes in incentive schemes for generators and the associated grid infrastructure, but also a more

How to cite this book chapter:

Froggatt, A. and Mitchell, C. 2020. Regulatory and policy incentives - how to establish governance for decentralised energy systems? In: Burger, C., Froggatt, A., Mitchell, C. and Weinmann, J. (eds.) Decentralised Energy - a Global Game Changer. Pp. 21-24. London: Ubiquity Press. DOI: https://doi.org/10.5334/bcf.b. License: CC-BY 4.0 
encompassing transformation of governance mechanisms - policies, institutions, market design and network rules, and the 'politics' behind them.

The starting point of today's regulatory framework was centralised systems. Historically, only one, or a few, entities owned and operated the grid and its associated infrastructure. Customers were passive receivers of a public infrastructure service. Many countries have not yet undertaken any reforms in the power supply industry at all, and vertically integrated, state-owned utilities are in charge of all operations along the value chain of the power sector. In other countries, reforms have been initiated, such as in South Korea, where competition is in principle allowed, but a single state owned company still dominates the market.

As described above, many countries are experiencing a phase of rapid decentralisation, however. This means new roles for, and new relationships between, stakeholders - whether resource providers, buyers, transmission operators, and so on. The idea of 'grids' will have to alter. They will be extended, interconnected, and more dynamic to operate flexibly, thereby incorporating variable renewables most cost effectively. Flexibility may become a key system function affecting large groups of dispersed individual suppliers.

In competitive electricity markets, such as in Western and Northern Europe, different customer segments emerge. Some individual consumers, as well as groups of consumers such as consumer co-operatives, may become producers and investors, and get involved in managing grids, whereas other consumers may choose to continue in their traditional role as customers and recipients of energy services. Some residential consumers may not even have an interest in switching their supplier, as their energy bill is just a small share of their income. For example, in Denmark - despite being a country where customers are invested in community projects - households have not tended to change electricity suppliers.

In situations where both individuals and groups of customers choose to become active agents, commercial opportunities for new entrants to provide services also occur. However, the energy system and its operations, the coordination and integration of smaller-scale services, and dispersed ownership, are also becoming more complex. Not only does it require greater flexibility for efficient operation, but it also requires greater data transparency and processing power of that data.

\subsubsection{An assessment of governance practices in key transformation countries}

Decentralising the energy system and establishing local markets, including local balancing markets, provide commercial opportunities for customers or producers, thereby adding a new dimension to the energy system - distributed, decarbonised, digitalised, and potentially democratised. Therefore, the role of 
regulation will change. It needs to be able to assign value to new services, to create a means of coordination between networks, markets, and new platforms in ways that are cost effective to customers, but also nimble and adaptive enough to enable, rather than undermine or block, innovation, new business models, and customer wishes.

The business models of these developing energy systems will differ depending on geography and sociocultural context, the legacies of the previous systemic configurations, and the size and pattern of demand. However, the way the business models develop in these different types of energy systems is also determined by where value - or payments - can be accessed within the energy value chain; and this in turn depends on the extent to which governance enables, constrains, or channels energy system innovation. Governance is at the centre of energy system transformation including the rate at which it is able to decarbonise.

The deployment and the development of decentralised energy differs across countries and regions, depending on the policy situation in which they develop. Within each country there are often distinct periods of renewables deployment, driven by different priorities in the policy regimes:

- Some countries, such as Denmark and Germany, which both have a long history of renewable energy deployment, have put renewables at the centre of their energy and electricity policy. The high level of deployment subsequently implies that an efficient integration of current and future volumes of renewables requires an increase in the flexibility of their energy systems.

- Emerging economies - such as China and India, characterised by rapidly growing power demand - have become global leaders in renewable technologies, including both manufacturing and deployment. These unprecedented high annual renewable installation rates may make small differences to their countries' overall power mixes, given the size of the existing supply portfolio, but the scale of these investments have indeed affected technology adoption internationally by driving down the price.

- There are regions in which renewable deployment is already affecting grid operation, such as South Australia or California.

- In other countries, where renewables play a less significant role, institutions have been slower to reform, so that the governance structure itself is becoming a limiting factor in the efficient deployment of decentralised renewables. For example, the Italian market is characterised by a remarkable increase in decentralised renewable capacity installed, despite the dominance of former incumbent utility Enel and the hesitation of regulatory bodies to introduce a coherent regulatory regime that embraces the next wave of the transition towards a fully decentralised system.

This chapter of the book looks at the current deployment practises in these countries, to assess the effectiveness of the policies and the impacts that higher contributions of renewables and decentralisation are having on system 
operation. The countries and regions were selected based on their historic, current, or expected importance to the global deployment rate of renewable energy and the contribution that renewables make to the overall electricity supply, and the system consequences. Some countries, for example the United States, which has a federal political model, have multiple, differing policies in different devolved states, which can illuminate the value of different governance mechanisms. The US chapter has been written as a comparative chapter in order to reflect this diversity. These country chapters can be allocated into two main categories:

- Countries or states with a high share of new renewable energies, but low or stagnant growth of per-capita primary energy consumption:

- Australia

- California and New York State

o Denmark

o Germany

○ Italy

- Countries or states with a low share of renewable energies and currently low levels of per-capita primary energy consumption, but on a fast economic development path:

- China

o India

The following sections of this chapter depict the diverging options governments have chosen to promote decentralised renewable energy supply. All contributions are independent yet interdependent narratives of the global momentum of the transformation of the energy supply industry. All of them emphasise the importance of regulation in the systemic changes, but they also show how the spectrum of trajectories - and their outcomes - are embedded in a pathdependent sociocultural and economic ecosystem that differs fundamentally across nations and continents.

\subsubsection{References}

GEA. (2012), Global energy assessment towards a sustainable future, GEA and International Institute for Applied Systems Analysis. Cambridge: Cambridge University Press.

Greenpeace. (2015), Energy [r] evolution - A sustainable world energy outlook, 2015, 100 percent renewable energy for all, 5th Edition.

IPCC. (2015), Renewable energy sources and climate change mitigation (Special report of the Intergovernmental Panel on Climate Change. Bonn: Intergovernmental Panel on Climate Change). 